\title{
Design of a Digital Game-based Learning System for Fraction Algebra
}

\author{
Oluwatoyin C. Agbonifo \\ Department of Information Systems, Federal University of Technology, Akure, Ondo State, Nigeria \\ E-mail: ocagbonifo@futa.edu.ng
}

Olutayo K. Boyinbode

Department of Information Technology, Federal University of Technology, Akure, Nigeria

E-mail:okboyinbode@ futa.edu.ng

\author{
Fisayo N. Oluwayemi \\ Department of Computer Science, Federal University of Technology, Akure \\ E-mail: oluwayemifisayo@gmail.com
}

Received: 20 May 2020; Accepted: 28 June 2020; Published: 08 October 2021

\begin{abstract}
Digital game based learning (DGBL) system is a promising area of research and debate, as it promotes contextualized learning, creates and harnesses motivation in learning capacities and encourages curiosity. DGBL takes place in a technological-mediated environment while engaging players in a learning activity through the support of computers. Several digital game based learning systems have been deployed for educational purposes to aid or support students in hands-on-learning experiences and constructive knowledge that involves mental reasoning processes. Hence, the research paper presented a development of digital game based fraction algebra learning system which is associated with game principle of snakes and ladders with underpinned concept of step-by-step procedure of solving mathematical problems. The system was tested by participants of FUTA staff primary school and the results of performance evaluation showed that the system could greatly support students to learn effectively the fraction algebra through game technology and would increase the students' thinking process.
\end{abstract}

Index Terms: Digital game based learning, fraction algebra, snake and ladder, mathematical problems

\section{Introduction}

The importance of education has been growing tremendously over the years especially in the modern days of digital technology. From ancient times, it has been noticed that practical learning has been more beneficial to the students in helping reinforce concepts better than books. Researchers and pedagogists tried to exploit advances in technology to integrate with traditional teaching techniques and develop methodologies with emphasis on "learning by doing" or "active learning" to help students learn better [1]. It has been observed that the latest advent of technology fascinating the children of today is the array of digital games. In recent years, it has been repeatedly suggested that embedding games into education can be a way to improve students' affect, interest, and motivation towards education, and in turn improve their learning [2].

Game-based learning (GBL) is a system where students play games with defined learning outcomes. Digital gamebased learning (DGBL) takes place in a virtual environment with fantasy elements while engaging players in a learning activity through the use of a technological tool such as a computer [3]. DGBL is a promising area of research and debate, as it promotes contextualized learning, creates and harnesses motivation in learning capacities, and encourages curiosity [4,5].

Research has proven that if mathematical concepts are embedded in these digital games, and considering the level of engagement children play these games with, it can significantly help to learn these mathematical concepts better in a more enjoyable manner coupled with their level of commitment [6]. Game design can be used specifically in mathematics education, as it promotes creative thinking and problem-solving skills that can be transferred to the classroom [7].

There are numerous applications that have been developed to take the advantage the gaming technology tends to offer when combines it with teaching and learning. But, the exploration of this technology in the area of mathematics as a subject has not fully utilized, especially when most students see the subject to be very difficult because it requires 
critical thinking and reasoning when solving mathematical problems in step-by-step procedural fashion. The use of game technology creates fun that makes for attraction or attention in gainfully engagement of problem solving. The learning of algebra using computer-mediated tool is also developed in $[8,9]$ but the use of gaming technology is not incorporated into it. Subsequently; Agbonifo and Onu [10] also developed a system using game theory of chess to solve algebraic expression using elimination by substitution, but solving algebraic fraction is not integrated into the system. Therefore, the research paper develops a digital game-based learning system using game logic of snakes and ladders to learn the concepts algebraic fractions in step-wise fashion.

\section{Digital Game based Learning}

According to Prensky [11], described digital game-based learning as any marriage of educational content and computer games. In an educational environment, the use of digital computer games offers the acquisition of knowledge construction opportunities [12]. Gaming is also considered as an activity that is interactive, entertaining and can make learning enjoyable [13]. Games can also be seen as the engagement of critical thinking through problem solving skills [14].

Games offer a unique structure to complement traditional strategies and infuse teaching with energy, spark innovative thinking and provide diversity in teaching methods which make learning concepts more palatable for students. Games encourage creative behaviour and divergent thought and are excellent ice breakers [15]. Games will often act as learning triggers inducing lively discussion on learning concepts amongst students following gameplay.

Keller [16] proposed ARCS model which enhances student learning motivation using the systemized instructional strategies as classified below and game characteristics employed in various design strategies. Keller conducted a study that made sure the processes reduce extraneous cognitive loads, enabling learners to establish schema through assimilation and accommodation, and increase germane cognitive loads.

The Attention, Relevance, Confidence and Satisfaction (ARCS) model is classified below with their subcategories, game characteristics and definition.

In the Attention category, digital games are designed with effects such as rich pictorial and auditory variations and using multimedia characteristics to induce players' curiosity. In addition, the use of story contributes to various types of knowledge learning. It comprises of different sub-categories such as perceptional arousal, inquiry arousal and variability. Its game characteristics are multimodal presentation and story, fantasy and fun.

In the Relevance category, the game tasks include tasks that accumulate toward achieving game goals, learners are often required to undertake a series of tasks to complete the final goal of the game [17]. Its sub-categories include goal orientation, motive matching and familiarity and it boasts of game characteristics such as tasks, goals, and sense of winning.

In the Confidence category, digital games constitute interactions between humans and machines, presenting players with a sense of performing actions. Its sub-categories are learning requirements, success opportunities and personal control. Its game characteristics are rules, control, play and interactive situations.

In the Satisfaction category, learners successfully complete tasks and accumulate scores, the sense of winning naturally induces a sense of achievement. Its game characteristics are sense of winning, outcomes and feedback. It comprises of sub-categories such as natural consequences, equity and positive consequences.

\section{Related Works}

Bouhineau et al.[8] carried out a study and concluded that Aplusix is a computer based system that favours the students' learning of algebra in school. Its basic training mode consists of letting the students perform their own calculations, it has a two-dimension editor of algebraic expressions, providing feedback on the correctness of the calculations and at the end of the given solution. Furthermore, the students gained autonomy and improved knowledge. Aplusix has a workspace area where the users type the solution to equation problems in a step-by-step manner. This is just a computer-mediated system and there is no incorporation of game technology into the system.

Feng et al.[18] developed a computer game which encourages players to combine numbers in different ways with arithmetic operators. It has been implemented in such a way that the players can either compete against another real-life player or the computer itself. This collaborative nature of the game encourages students to learn concepts better via teamwork and competition. This game mechanism encourages students to learn fractions in a dynamic grouping environment. A future improvement for the game is proposed that would be needed to maintain individual data logs of each student's learning process, which could be further analysed to build students' specific models and detect the cognitive aspects. The focus of problem-solving is not on fraction algebra.

Turtiainen et al. [9] conducted a study on UFraction as one of the latest story based fraction games that was developed for mobile devices and was tested on eighth grades students in five South African schools; and on students and teachers of the University of Pretoria, South Africa. The story in UFraction revolves around mother leopard and her cub senatala, which the students tend to identify themselves with. This platform facilitates development of multiuser, networked mobile applications on Java enabled mobile devices. The goal of the game is to solve problems 
using Hungarian Mathematical manipulative, which are collections of twelve coloured rods, each having a different colour and length. Though, the system is based on story-based structure of solving fractions but not on fraction algebra.

Cognitive Tools (CT) is another educational tool by Kong [19] which uses exploratory process to teach students the procedural knowledge of adding and subtracting fractions. These fractions can have like and unlike denominators. The CT is a web-based learning tool. It uses graphical representation of fractions to utilize students' initial knowledge of the part-whole concept of fractions. Teachers found this tool effective in tutoring students and likewise the students found this tool stimulating as well. This tool was used in pre-test-post-test control group empirical study and has been discovered to have potential for the development, which could enhance collaborative learning of fraction concepts among students in classroom. The system did not incorporate fraction algebra which is another mathematical concept in problem-solving.

Agbonifo and Ogunmoroti [20] developed a digital lego-based learning environment for fraction ordering and it is a digital game which involved a boy plucking fruits before he gets home within a specified time. To pluck the fruits, he needs to break some fraction cube in ascending order within a timeframe hence making the game align with the learning process. If the cubes are broken in the digital was tested amongst ten pupils in one of the private schools around the Federal University of Technology, Akure (FUTA). The area of focus of the system is on fraction ordering and not on fraction algebra.

Bouzid et al. [21] developed a beta-prototype educational digital game for supporting elementary mathematics learning that focused on reducing the intensity of emotional barriers and boosting concentration, motivation, autonomy and interaction. The finding shows that the impact of the build-from-scratch DGBL approach pays off in primary school.

Agbonifo and Onu [10] developed a digital game based on chess mediated environment which provides the player with the problem-solving sequences of simultaneous equations using elimination method. The game has a storyline where a king in one kingdom is abducted by opposing kingdom and a brave knight embarks on a mission to rescue the King. The rule of the game is to resolve two simultaneous equations of order 1 . This is finding the values of the two unknown variables ( $\mathrm{x}$ and $\mathrm{y}$ ) which act as the keys needed to unlock the enemies' gate and the King's prison gate with a fraction of time allocated to each scene. The digital game-based learning system did not accommodate solving of algebraic expression with fraction.

\section{System Design}

The section describes the storyline of the game, system architecture, flowchart and modules.

\section{A. Game Description}

\section{i. $\quad$ Storyline of the game}

The storyline of this game is based on snakes and ladders concept but the player is not required to go through boxes $0-100$ ) and go through up or down by using ladders in the original concept of snakes and ladders game. Now the player has to make the snake hurdle through the 4-step ladder by solving the fraction question presented to him where he would use instructions displayed on the screen to solve the fraction algebraic question. With the instructions displayed, the user should be able to learn and solve as many questions as possible. For the user to obtain the maximum score, he should be able to supply the answers at each step of the ladder before proceeding to solve the main fraction algebraic question.

\section{ii. Game Play}

Firstly, the player has to solve all the simple fraction questions on the ladder by making the snake entity successfully get to the top of the ladder before solving the fraction algebraic question that would be presented to him. There would be steps and instructions as to how he should be able to solve the algebraic question. The following steps below highlights how the user can traverse before obtaining the maximum score:

(i) The player should be able to solve all the fraction question

(ii) In the first process above, if the player gets each question correctly, the snake is moved up by one step.

(iii) If the player is successfully able to beat the time count, then he/she is added to the top of the leader-board and can replay the game again as he/ she wishes to.

With the game play and story development, the user has to ensure that the snake has to be at the top of the ladder before testing his knowledge on the subject matter by solving the fraction algebraic question. Steps/instructions displayed to the player should be able to guide him in achieving the ultimate goal.

\section{iii. Timing System Used of the Game}


The timing system defines how well the player is able to beat the time in achieving very high scores and being top of the score chart. Most timing system in games is counted downwards so as to give the player a sense of attention and confidence as in the ARCS model. The unit of timing system used in the project is in seconds.

\section{iv. Scoring System Used for the Game}

The scoring system connotes who gets the highest score and the processes on how the scores are being achieved. The process of scoring is simple, in that whenever the player accomplishes a task within the game, the player is rewarded with more points to get his/her desired score. The scoring system is limited to numeric score. As long as the player follows the rule of the ladder game and solves different algebraic questions, more points are added to him. This is how scoring systems work in most games and the unit of the scoring system is in numbers (points). Most players would always want to be at the top of the leaderboard as it encourages competition amongst players which makes them to be classified as champions.

\section{B. System Requirements}

The system is developed using the Visual Studio Integrated Development Environment (IDE). The system runs on almost any Windows platform. The server side has both the application logic layer and the database layer and it is required to be a high end machine. The minimum requirements at the server side include Structured Query Language (SQL) Server, browser and SQL Server full text search. The minimum requirements at the client side include Intel Pentium IV/M processor running at $400 \mathrm{MHz}-1.7 \mathrm{GHz}, 512 \mathrm{MB}$ RAM and SVGA Monitor.

\section{System Architecture}

The system architecture is depicted in Fig. 1 which is based on Microsoft .NET Framework that provides powerful technology such as Windows Forms to simplify developing applications and components that work seamlessly on the windows machine. It consists of components such as game interface, game input, game logic, database and the corresponding output. The game interface is a communication platform through which the user can access the system. The game input to the system by the users is carried out through mouse and keyboard allowing users to navigate through the game process. Inputs to the game are player name, password, and steps into each stage as required by responding through clicking. The game logic employs the propositional logics.in the development of the game which defines the logical outcome of the game and all the working processes. The game uses combination buttons (ladder steps) to successfully fast track the snake by reaching the top of the ladder to start the main game which is done by solving a fraction algebraic question. The database, Microsoft Structured Query Language (MSSQL) Server is used to keep record of scores and results of the user engagement and experience in the game. While the output represents the outcomes of the game based on the inputs provided via keyboard and mouse clicking events and the logics with which user response are implemented.

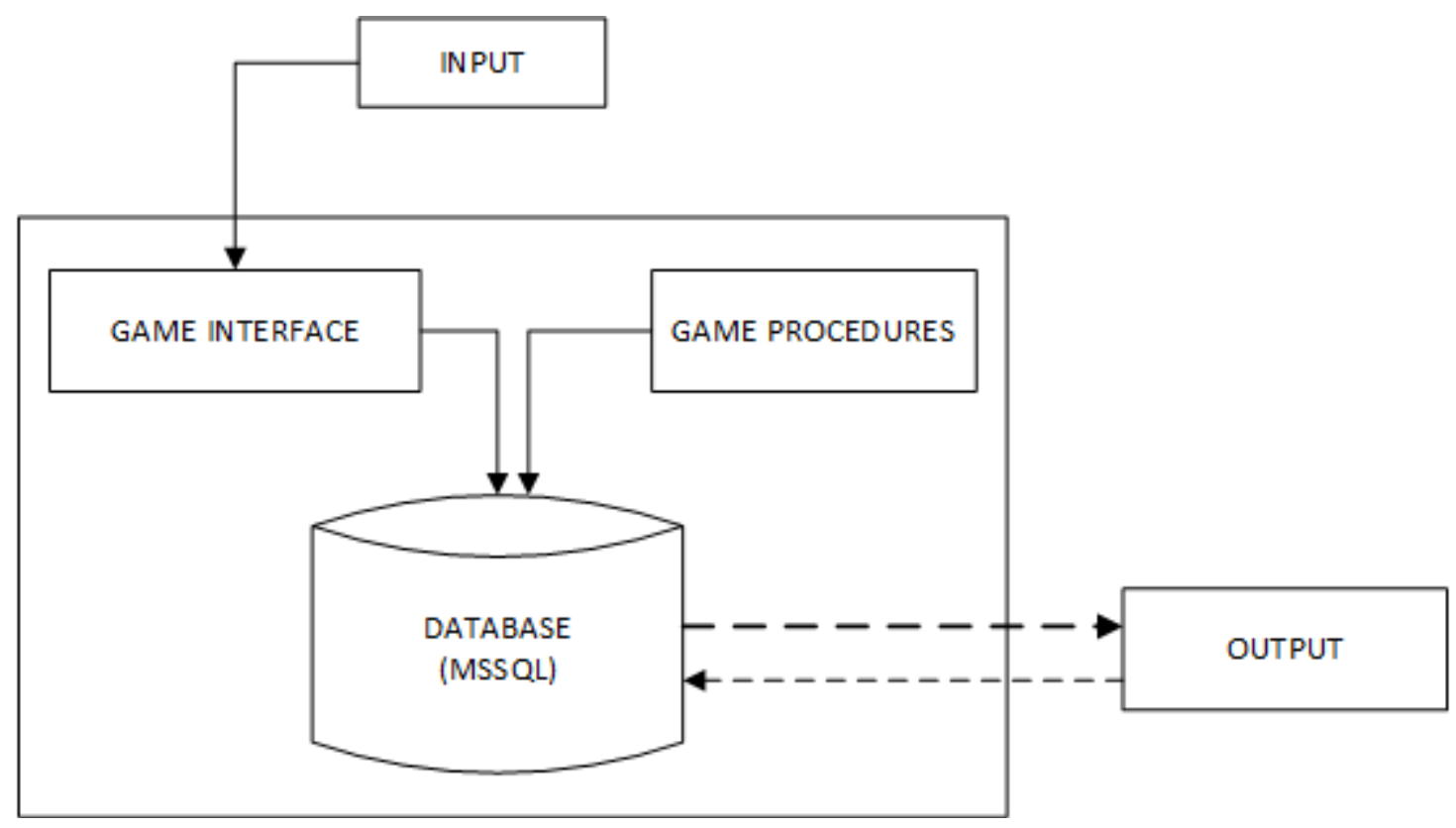

Fig. 1. System Architecture 


\section{System Flowchart}

The flowchart of the fraction algebraic system is depicted in the Fig. 2 which shows a procedural representation of event happening within the game. As the game is launched, it provides the player with menu options to play, exit, check scorer board for high scorer or even check what the game is about. If the option selected is exit, the game exits. If the option selected is high score it checked the database. If the option is "play", it registers the player and verifies if the user is registered, hence, the player can start playing the game according to the rules of the game. Once the user clicks on the start button, a fraction algebraic question is displayed on the system for the user to solve. There is a timer of 420 seconds ( 7 minutes) counting down and if the game timer is equals to zero seconds, then the game prompts a message telling the player that he has exceeded the time frame, else, the user continues until he achieves the correct answer and maximum score is obtained. If the player completes the task required by the game, points are being awarded and saved to the database.

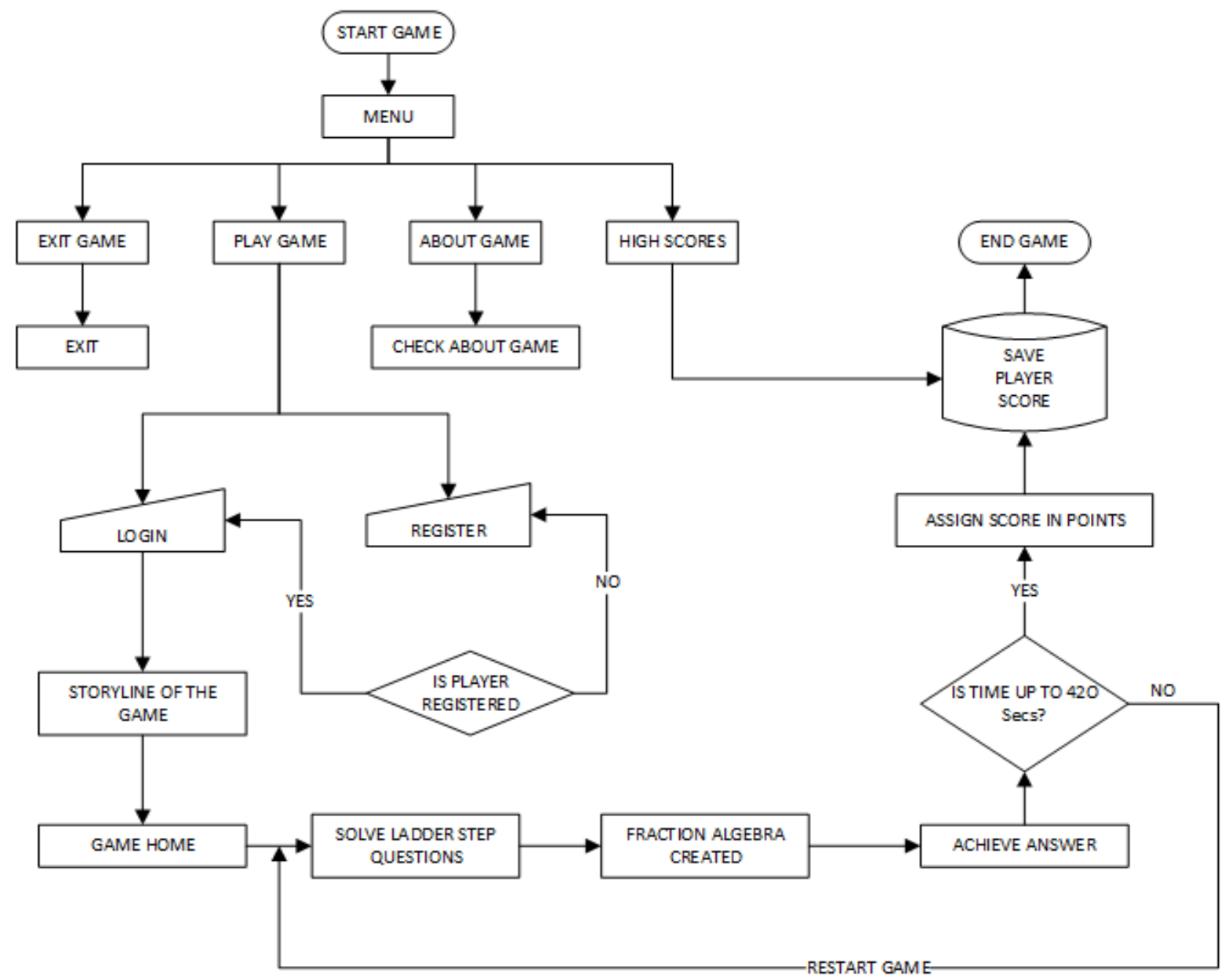

Fig. 2. System Flowchart

\section{E. System Modules}

System modules are the set of programs that are composed of one or more independently developed linked modules which gives the system efficient and effective performance. Fig. 3 shows the interface of C\# class file developed in the Visual Studio.NET suite for designing the game interface (Fig. 4) which runs on a library called the .NET Framework. 


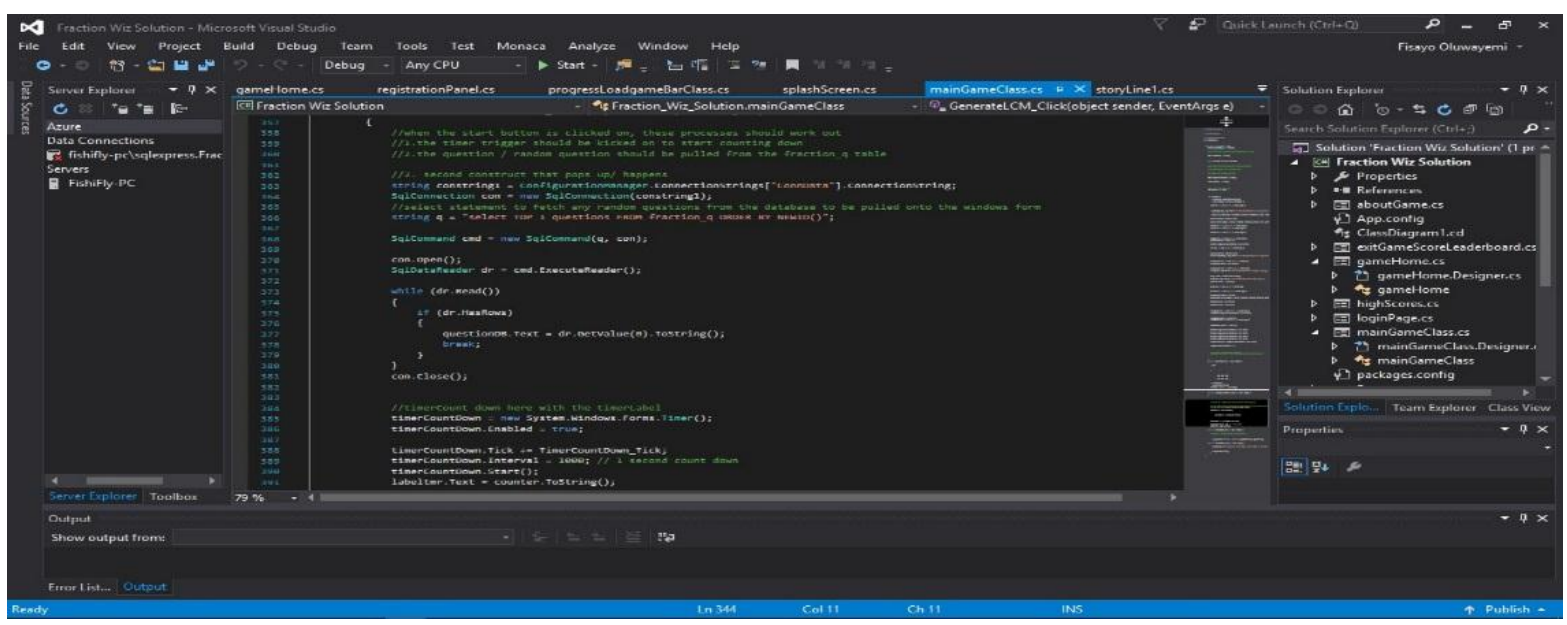

Fig. 3. Design Process of the Game

Fig. 4 describes the game interface which displays the interaction of the player with the system and consists of the components such as Play, High Scores and Exit Game. The Play button takes the player into the login page to register his/her login details and for subsequent authentication and verification processes It also checks if such player has registered in the SQL database in order to grant the player login access. The High Scores button displays a list of high scores achieved by the player and the exit game button ends the game.

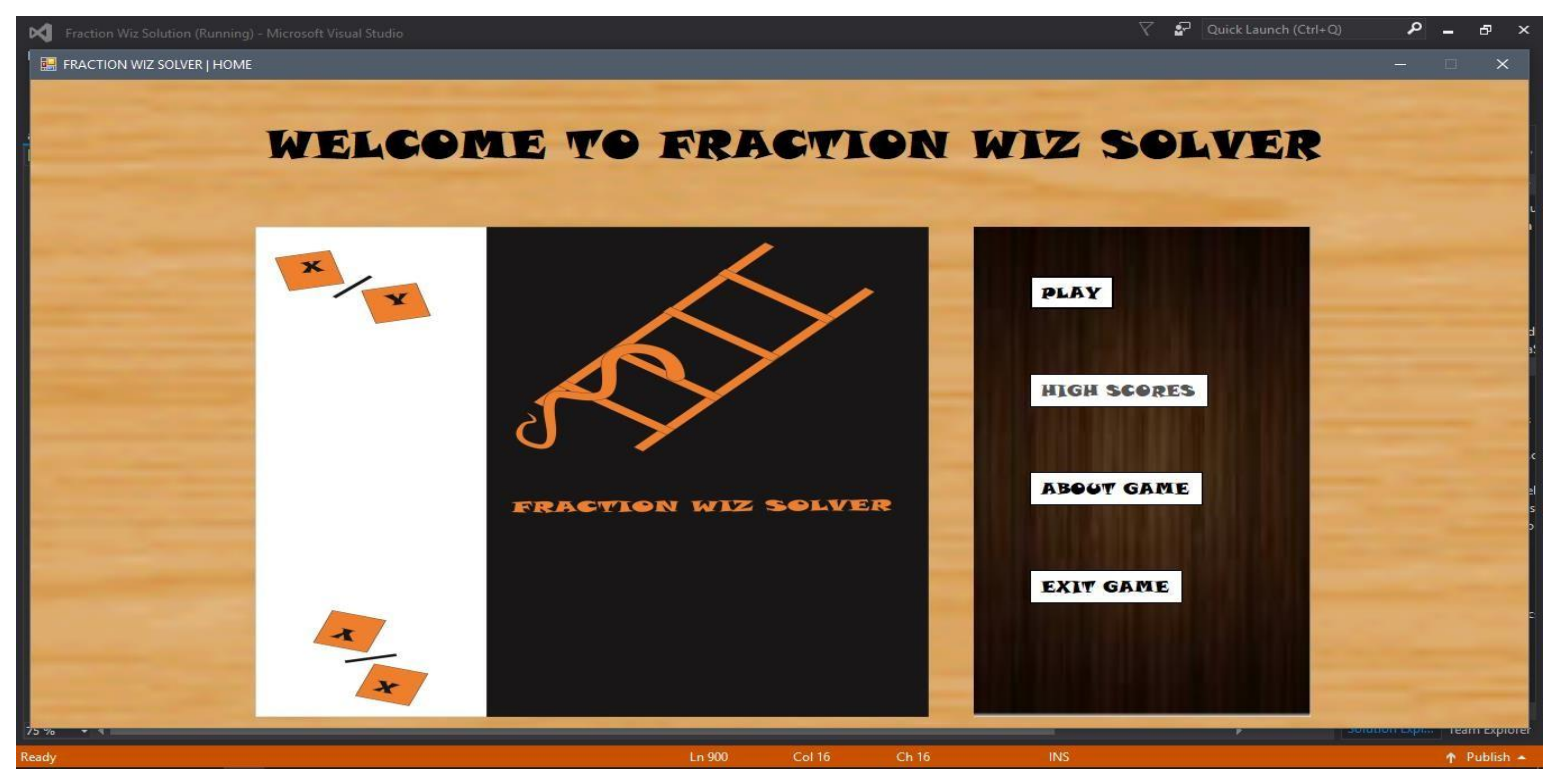

Fig. 4. Game Interface at Runtime

Fig. 5 presents the platform for player to solve fraction algebraic which consists the various components such as timing, score, 4-ladder steps and fraction algebraic question. At the start of the game, fraction algebra would randomly be generated where the player provides step-wise solving of the question in 4-ladder steps. The outcome of one step is an input to the next step until the final solution of the question. There are various hints provided in each of the steps that would assist the player on problem solving. A fraction algebraic question pops up for a player to solve with the game logic panel at the right side. If the player follows each instruction carefully, he would be able to proceed to the top of the last ladder. There are bar levels situated at each step of the ladder to boost the player's level of confidence. Once each step is solved right, a snake appears at each step of the ladder indicating his progress. 


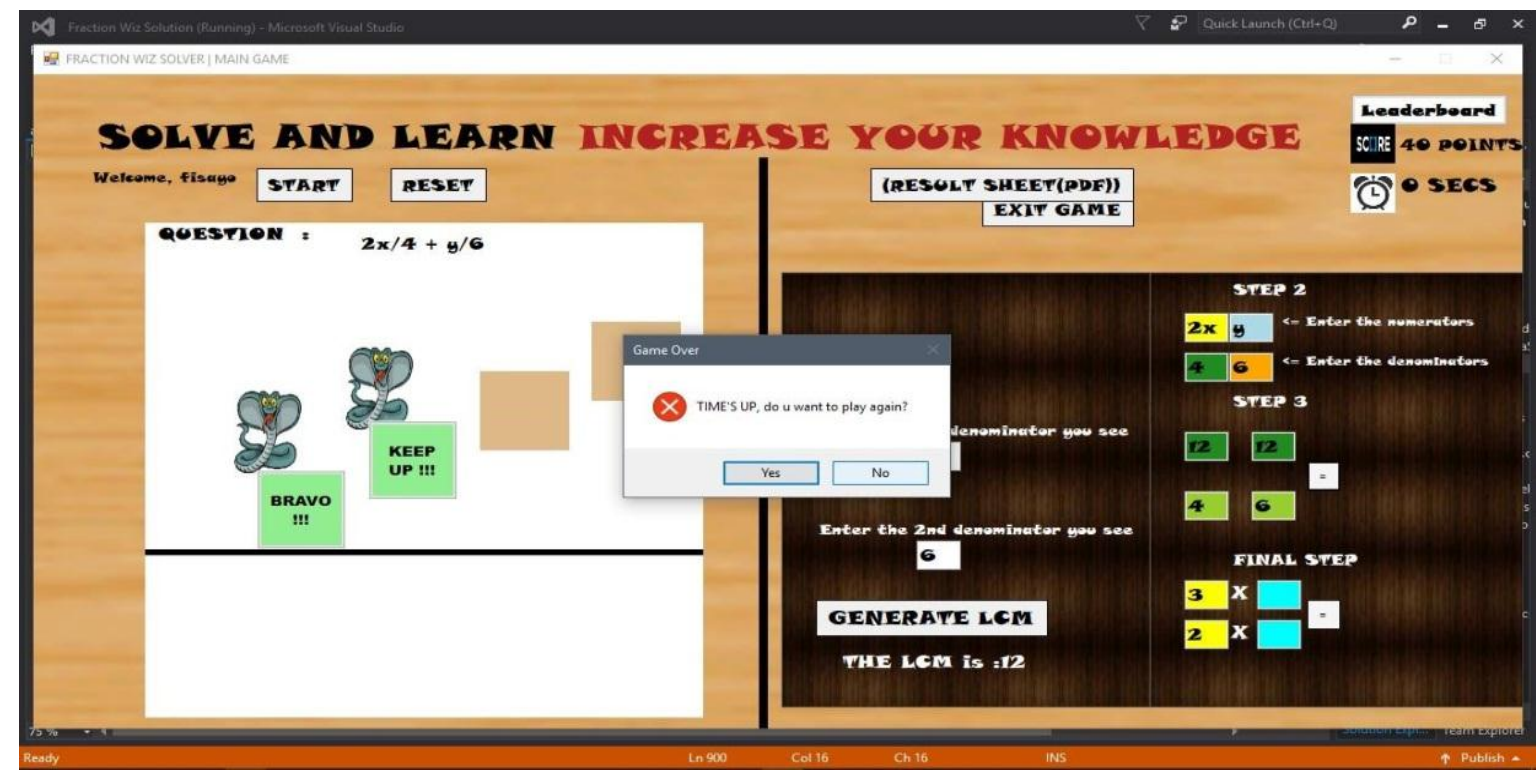

Fig. 5. Sample of a Player's Process of Problem Solving

\section{Sample of Game Logic}

This section explains the game logic of the system as follows:

The Values that are to be entered in the 2 white boxes with the hint "Generate lowest common factor (LCM) button" are the 2 denominators of the fraction algebraic LCM question.

Value in the first white box $=$ denominator 1 of the random question

Value in the second white box $=$ denominator 2 of the random question

After entering the values, the button is being clicked to generate the LCM for the player; after which he proceeds into the STEP 2 of the game.

At this STEP 2, the player is required to enter the numerators and denominators of the random question given to the player in the coloured boxes: yellow, aqua, green and orange.

The first two boxes yellow and aqua are for the numerators while the second two boxes green and orange are for the denominators.

The player then proceeds into the STEP 3 part of the game where he is required to enter the LCM being generated from the two (2) white boxes values entered at the STEP 1. For example, in Figure 5, the algebraic question is generated after the player clicks on the start button.

$(2 x / 4+y / 6)$ - Fraction algebra question is generated at the start button. When the values 4 and 6 are entered in the white boxes, it generates the LCM from the given question. This LCM value is to be entered twice in the dark green boxes followed by the denominators of the algebraic question.

When these values are entered correctly, the division process takes place which inputs the correct values inside the yellow boxes in the final step.

At the final step, the player is required to enter the numerators of the algebraic question presented after which the final solution is displayed.

\section{System Result}

The Table 1 depicts the sample of twenty players' scores out of sixty four players from FUTA Staff School that actively participated in this game. The varied scores show that those that have more points demonstrate the high level of understanding in subject matter. 
Table 1. Sample of Game Score of Players

\begin{tabular}{|c|c|}
\hline PLAYERS' IDENTICATION & SCORES \\
\hline Player1 & 110 \\
\hline Player2 & 40 \\
\hline Player3 & 80 \\
\hline Player4 & 130 \\
\hline Player5 & 60 \\
\hline Player6 & 120 \\
\hline Player7 & 150 \\
\hline Player8 & 130 \\
\hline Player9 & 120 \\
\hline Player10 & 150 \\
\hline Player11 & 120 \\
\hline Player12 & 200 \\
\hline Player13 & 70 \\
\hline Player14 & 170 \\
\hline Player15 & 160 \\
\hline Player16 & 110 \\
\hline Player17 & 120 \\
\hline Player18 & 100 \\
\hline Player19 & 200 \\
\hline Player20 & 40 \\
\hline
\end{tabular}

\section{Performance Evaluation}

The system was tested by a set of pupils in primary 4 (39), primary 5 (21) and primary 6 (4) with a total of 64 pupils. There were thirty four (34) female and thirty (30) male. The survey analysis was conducted in FUTA staff primary school in which the pupils actively engaged themselves with the digital game based system in the learning of fraction algebra.

There were thirty seven (37) questions drawn which are distributed across the criteria in this category: Ease of use (8), Intuitive User Interface (8), Optimisation (8), Improvement for Calculating Skills (8), and Correctness of Results (5). The data were obtained by assigning values of 4, 3, 2 and 1 to the linguistic term "Strongly Agree", "Agree", "Strongly Disagree" and "Disagree" respectively. The survey was distributed to a set of sixty four players. The analysis of the respondents with respect to the questions for the criteria is presented in Table 2. The responses of the players were analysed to determine the performance of the system based on the criteria using mean and standard deviation (SPSS 17.0). The result of the analysis is presented in Table 3 which considering the minimum and maximum values for each criterion with respect to the mean and standard deviation demonstrates that the system performs relative good. This indicates that the majority of the participants made positive affirmation that they strongly agreed or agreed with the followings: the system is easy or simple to use, the user interface is friendly, flexible and easy to navigate; system's response time in solving the problem with time frame allotted is efficient; the system enhances the students' knowledge in step-by-step problem-solving skills of fraction algebra; and that the modality in which the system presents the results or learning outcome is in a. realistic mathematical concepts connotation and hints are provided to assist players in the understanding of providing solution to fraction algebraic problems in a logical reasoning manner. 
Table 2. Analysis of the Respondents with Respect to the Questions

\begin{tabular}{|c|c|c|c|c|c|}
\hline QUESTIONS & $\begin{array}{l}\text { STRONGLY } \\
\text { AGREE }\end{array}$ & AGREE & $\begin{array}{l}\text { STRONGLY } \\
\text { DISAGREE }\end{array}$ & DISAGREE & TOTAL \\
\hline Ease of Use & 22 & 30 & 5 & 7 & 64 \\
\hline $\begin{array}{ll}\text { Intuitive } & \text { User } \\
\text { Interface } & \end{array}$ & 25 & 26 & 5 & 8 & 64 \\
\hline Optimisation & 28 & 29 & 3 & 4 & 64 \\
\hline $\begin{array}{l}\text { Improvement of } \\
\text { Calculating Skills }\end{array}$ & 27 & 29 & 4 & 4 & 64 \\
\hline $\begin{array}{l}\text { Correctness of } \\
\text { Results }\end{array}$ & 26 & 30 & 4 & 4 & 64 \\
\hline
\end{tabular}

Table 3. Result of Analysis of System Performance Evaluation

\begin{tabular}{|c|c|c|c|c|c|c|}
\hline & $\mathrm{N}$ & Minimum & Maximum & Sum & Mean & Std. Deviation \\
\hline Ease of use & 64 & 16.00 & 32.00 & 1552.00 & 24.2500 & 4.57391 \\
\hline Intuitive User Interface & 64 & 15.00 & 32.00 & 1582.00 & 24.7188 & 4.62385 \\
\hline Optimsation & 64 & 12.00 & 34.00 & 1671.00 & 26.1094 & 4.48673 \\
\hline Improvement of Calculating Skills & 64 & 13.00 & 32.00 & 1672.00 & 26.1250 & 4.59986 \\
\hline Correctness of Results & 64 & 8.00 & 20.00 & 1023.00 & 15.9844 & 3.11928 \\
\hline Valid N (listwise) & 64 & & & & & \\
\hline
\end{tabular}

\section{Conclusion}

The method of solving mathematical concepts always involves hands-on-approach that requires stepwise theoretical-based solutions to the mathematical questions or problems. In the same vein, critical and constructive thinking are most crucial components needed in problem solving process. From experience, the use of solving with paper and pen has been proven to be difficult and boring on the part of learners due to the nature of the concepts. From the literature, the integration of gaming technology to solve mathematics problems has been of great assistance to all learners in various levels of institutions of learning. Hence, this digital game-based system is developed to support mental reasoning skill in problem solving process and includes game step bars to boost the player's confidence when solving to achieve a defined solution. The system would serve as a supporting tool to complement the teaching methods and strategy of instructors or teachers, thereby promoting clearer understanding of the concept on the part of the students.

\section{References}

[1] A. Serdar, Game-based Improvement of Learning Fractions Using IOS Mobile Devices, Master of Science Thesis Submitted to the Faculty of the Virginia Polytechnic Institute and State University, Placksburg, Virginia., 2011.

[2] K. Squire, Video Games in Education, International Journal of Intelligent Simulations and Gaming, Vol 2, Issue1, pp. 49-62, 2003.

[3] R. Teed, Game-Based Learning. Retrieved from the Carleton College, Available at: http://serc.carleton.edu/introgeo/games/index.html, Accessed on May, 2017.

[4] J. Gee, Learning and Games. In K. Salen (Ed.), The Ecology of Games: Connecting Youth, Games and Learning pp. 21-40, 2008.

[5] J. Kirriemuir and A. McFarlane, Literature Review in Games and Learning. Bristol: Nesta Future Lab, pp. 10 - $20,2004$.

[6] M. Prensky, Digital Game-Based Learning: Exploring the Digital Generation, Educational Technology, U.S. Department of Education, pp $20-60,2003$.

[7] Q. Li, Digital game building: Learning in a participatory culture. Educational Research, 52(4), pp 427-443, 2010.

[8] D. Bouhineau, J-F. Nicaud, H. Chaachoua, M. Bittar and A. Bronner, Two Years of Use of the Aplusix System. Proceedings of WCCE'2005, the 8th IFIP World Congress on Computers in Education, pp 1301 - 1311, 2005.

[9] E. Turtiainen, S. Blignaut, C, Els, T. H. Laine and E. Sutinen, Story-Based UFractions Mobile Game in South Africa: Contextualization Process and Multidimensional Playing Experiences, In Proceeding of the Second Workshop Story Telling and Educational Games, South Africa, 2009.

[10] O. C. Agbonifo and O. P. Onu, Development of a Digital Game-Based Algebraic Learning System, International Journal of Scientific and Engineering Research, 8(12) pp.863-869, 2017.

[11] M. Prensky, Digital Game-Based Learning. New York: McGraw-Hill, pp 1-20, 2001.

[12] G. Garcia, Digital Game Learning. In B. Hoffman (Ed.), Encyclopedia of Educational Technology, pp 200- 300, 2005.

[13] C. Aldrich, Simulations and the Future of Learning. San Franscisco, CA, pp. 534 -581, 2004.

[14] D. H. Schunk, Learning Theories: An Educational Perspective (4th ed.). Upper Saddle River, NJ: Merrill \& Prentice Hall, pp. 23- 45, 2004.

[15] B. Fuszard, Gaming. In Lowenstein, A. J., Bradshaw, M. J. \& Fuszard, B. (eds.) Fuszard's Innovative Teaching Strategies in Nursing. 3rd ed. Gaithersburg, MD, Aspen Publishers, pp. $234-500,2001$. 
[16] J. M/ Keller, Strategies for Stimulating the Motivation to Learn. Performance and Instruction, 26(8), pp. 1-7, 1987.

[17] W. Huang and T. Johnson, Instructional Game Design using Cognitive Load Theory. In R. Ferdig (Ed.), Handbook of Research on Effective Electronic Gaming in Education, pp. 1143-1165, 2008.

[18] K., B. Chang, C. Lai and T. Chan, Joyce: A Multi-Player Game on One-on-One Digital Classroom Environment for Practicing Fractions, In Proceedings of the Fifth IEEE International Conference on Advanced Learning Technologies (ICALT'05), pp. 543-544, 2005.

[19] S. C. Kong, The Development of a Cognitive Tool for Teaching and Learning Fractions in the Mathematics Classroom: A Design-Based Study, Computers \& Education 51 (2), pp. 886-899, 2008.

[20] O. C. Agbonifo and A, O, Ogunmoroti, A Digital Lego-Based Learning Environment for Fraction Ordering, Nigerian Journal of Technology, 34(4) pp. 781-787, 2015.

[21] T. Bouzid, H, Darhmaoui and F. Kaddari, Promoting Elementary Mathematics Learning through Digital Games, Proceedings of the 2nd International Conference on Big Data, Cloud and Applications, http://dx.doi.org/10.1145/3090354.3090451, 2017.

\section{Authors' Profiles}

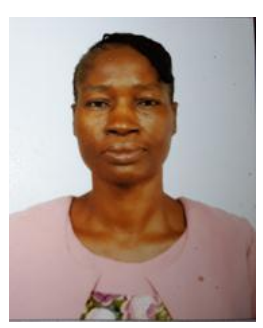

Oluwatoyin C. Agbonifo obtained her PhD degree in Computer Science from the Federal University of Technology, Akure, Nigeria. She is an Associate Professor in the Department of Information Systems, Federal University of Technology, Akure, Nigeria. She has authored/co-authored a number of articles at both local and international refereed journals and conference proceedings. She is a regular reviewer in local as well as international scientific/academic journals. She is a member of the NCS, CPN, IEEE, AACE and OWSD. Her research interest areas include: Personalised and Adaptive Ubiquitous learning, Digital Game-Based Learning, Software Engineering and Artificial Intelligence.

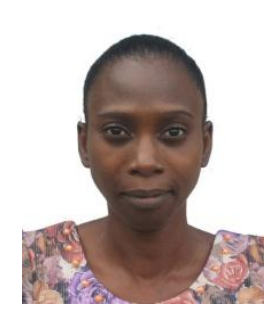

Olutayo K. Boyinbode PhD is an Associate Professor at the Department of Information Technology, Federal University of Technology, Akure, Nigeria. Her research interests are in Mobile and Ubiquitous Learning, Mobile Networks, Machine learning, Information and Communication Technology for Development (ICT4D), Internet of Things for Development (IoT4D) and Business Intelligence. She has over 60 publications in reputable peer-reviewed Journals and conference

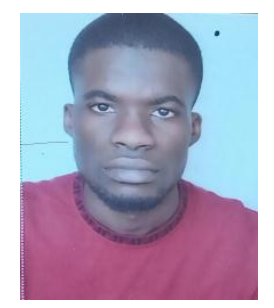

Fisayo N. Oluwayemi obtained his B.Tech. degree from Computer Science at the Federal University Technology, Akure, Ondo State, Nigeria with second class upper division in the year 2017. He is a software engineer by profession. Presently, he is working with Wellahealth Technologies.

How to cite this paper: Oluwatoyin C. Agbonifo, Olutayo K. Boyinbode, Fisayo N. Oluwayemi, " Design of a Digital Game-based Learning System for Fraction Algebra", International Journal of Modern Education and Computer Science(IJMECS), Vol.13, No.5, pp. 32-41, 2021.DOI: 10.5815/ijmecs.2021.05.04 